\title{
The rookie and the old-timer: challenges and future prospects
}

\author{
Rodrigo Guimarães ${ }^{1}$
}

Published online: 1 March 2019

(c) Springer Nature B.V. 2019

In late 2018 when I was approached to join the editorial team of Molecular Biology Reports (MOLE) and act as a managing editor, my brain cells started to work overtime. This was a completely new challenge in my scientific career, one that I had wanted for a long time and was looking forward to embrace while also thinking to myself "what am I getting into?'. After putting both feet back on the ground, I realized this was an opportunity to help fellow researchers share their findings with the world and with that shape how the scientific knowledge field looks like. So, I accepted the task and was introduced to MOLE, a journal with solid roots in the publishing community and which has been around for more than 40 years. MOLE was going through a thorough reorganization with the purpose of providing the journal the means to better serve the authors that chose to trust MOLE with the task of spreading their findings to the scientific community. Nowadays, authors have a huge number of publication options and an increased pressure to publish. At the same time, there is this perception and sometimes reality that the success of their career depends on being accepted into a high impact factor journal. It is therefore not surprising that authors look at journal selection as a taunting task with major impact in having or not a place in academic research.

In an attempt to help, one of our aims as the editorial team behind MOLE is to deliver the best possible experience regarding the entire submission process. We aim to deliver a fast, accurate and fair decision to authors. We are also aware of the lack of training many young researchers have in regards to submission skills or even scientific writing so we try and help by being approachable and always working together with the author. This availability does not impact our golden rules of impartiality, reproducibility and technical accuracy when it comes to assessing a manuscript quality. As an additional effort to help authors worldwide, we have decided to explore some of the key research trends

Rodrigo Guimarães

rodrigo.soaresguimaraes@springernature.com

1 Dordrecht, The Netherlands by inviting submissions on these areas. We will be focused, throughout 2019, in receiving not only review articles on these subjects but also by organizing a number of special issues.

The areas we will try to cover are: long noncoding RNA's, regulation of cell fate and nanotechnology. We see an increase in attention in the role of long noncoding RNA's with several studies suggesting ln RNAs are responsible for a wide range of modifications that include, among others, the regulation of miRNA expression [1-3]. Building on the debate of cell fate will also be of interest. Discussing the molecular intricacies between senescence and quiescence will be of significance to improve the understanding of the origin, progression and treatment of cancer [4]. In line with the subject of cancer, we at MOLE, find the field of nanotechnology to be on the frontier of technological advance. The fast developments in nanotechnology have already had an extensive impact in several life science areas including healthcare. The use of nanoparticles for therapeutic purposes is well on the way especially when it comes to chemotherapeutic agents with low levels of solubility where the development of nanocarriers would improve the water solubility of these agents. In addition to this the co-delivery of these agents together with a secondary substance [5], has proved to improve the outcome of chemotherapy.

We are keen to see the outcome of these editorial changes, hoping this is just the beginning of something bigger. We are excited to keep building on the strong foundations of MOLE and keep providing authors a solid and reliable service. In the short term, we hope to position the journal in the scientific community in such a way that, research groups will look at MOLE as a good first candidate to publish their work. Lastly, the editorial team would like to extend their appreciation to all authors that trust us with the task of reading firsthand their research, to all the peer reviewers that on a daily basis work with us and keep our content solid and sound, and finally, to our board members for devoting their valuable time to assist the editorial team with their expertise. We look forward to hearing from you, not only how you experienced 
publishing with us but also any suggestions you might have about how we can improve the journal.

\section{References}

1. Sun J, Wang X, Fu C et al (2016) Long noncoding RNA $\mathrm{FGFR}_{3}$-AS1 promotes osteosarcoma growth through regulating its natural antisense transcript FGFR 3 . Mol Biol Rep 43:427. https ://doi.org/10.1007/s11033-016-3975-1

2. Rao AKDM, Rajkumar T, Mani S (2017) Perspectives of long non-coding RNAs in cancer. Mol Biol Rep 44:203. https://doi. org/10.1007/s11033-017-4103-6
3. Majidinia M, Mihanfar A, Rahbarghazi R et al (2016) The roles of non-coding RNAs in Parkinson's disease. Mol Biol Rep 43:1193. https://doi.org/10.1007/s11033-016-4054-3

4. Terzi MY, Izmirli M, Gogebakan B (2016) The cell fate: senescence or quiescence. Mol Biol Rep 43:1213. https://doi. org/10.1007/s11033-016-4065-0

5. Minaei A, Sabzichi M, Ramezani F et al (2016) Co-delivery with nano-quercetin enhances doxorubicin-mediated cytotoxicity against MCF-7 cells. Mol Biol Rep 43:99. https://doi.org/10.1007/ s11033-016-3942-x

Publisher's Note Springer Nature remains neutral with regard to jurisdictional claims in published maps and institutional affiliations. 